\title{
Does oyster mushroom (Pleurotus sajorcaju) powder addition improve nutrient composition, sensory acceptability, and glycaemic index (GI) of flatbread (Tortilla)?
}

\author{
Wan Rosli WAN ISHAK ${ }^{1, *}$, Wan Amir Nizam WAN AHMAD ${ }^{2}$ and Nordiana ABU BAKAR ${ }^{1}$ \\ ${ }^{1}$ Nutrition and Dietetics Program, School of Health Sciences, Universiti Sains Malaysia \\ Kota Bharu, Kelantan, Malaysia \\ ${ }^{2}$ Biomedicine Program, School of Health Sciences, Universiti Sains Malaysia \\ Kota Bharu, Kelantan, Malaysia \\ * Corresponding author: wrosli@usm.my
}

\begin{abstract}
Regular consumption of dietary fibre (DF) has been proven to reduce the risk of non-communicable diseases, which leads to the rising demand for DF-enriched products. The study aims to investigate the effect of Pleurotus sajorcaju powder (PSP) incorporation on the nutrient composition, sensorial acceptability, and glycaemic index (GI) of the developed tortilla. Four tortilla formulations with different PSP levels $(0 \%, 5 \%, 10 \%$, and $15 \%)$ to replace wheat flour partially were prepared. The control tortilla's protein concentration was $8.26 \%$ and increased to $9.31,9.72$, and $10.60 \%$ when incorporated with 5, 10, and 15\% PSP, respectively. Both the $10 \%$ and $15 \%$ PSP tortilla $(12.00 \%$ and $13.62 \%$ ) were found to be significantly higher than the control tortilla in total DF. The $\beta$-glucan content was the highest in the tortilla with $15 \%$ PSP added (1.21\%). In sensory evaluation, the tortilla fortified up to $15 \%$ PSP was apparently well accepted by the sensory panelists. Control tortilla had an intermediate GI value (58) while 15\% PSP tortilla had a low GI value (53). In summary, adding up to $15 \%$ PSP in the tortilla formulation increased nutritional values, improved sensorial attributes, and reduced GI value.
\end{abstract}

Keywords: Glycaemic index (GI); nutrient; Pleurotus sajorcaju; sensory evaluation; tortilla.

\section{Introduction}

Presently, the prevalence of noncommunicable diseases (NCDs) is rising at a remarkable rate and becoming a main public health issue throughout the world, including Malaysia. The NCDs include cancers, chronic respiratory diseases, cardiovascular diseases, and type 2 diabetes mellitus (T2DM) are the main factors of fatality in the world (Zheng et al., 2018). The prevalence of NCDs is increasing swiftly and is predicted to exceed as the common causes of mortality by 2030 (Zheng et al., 2018). The increased NCDs rate is proportionally associated with the low intake of DF in individuals' daily meals or diets. DF is an important nutrient in our staple diets and naturally exists in nuts, cereals, fruits, vegetables (Dhingra et al., 2012), and fungi ( $\mathrm{Ng}$ et al., 2017). Sufficient daily intake of DF has been scientifically proven to decrease certain NCDs' risks such as colorectal cancer, cardiovascular diseases, diabetes, and obesity (Lattimer et al., 2010; Jochem \& Leitzmann, 2016). 
Among many types of edible fungi, oyster mushrooms (Pleurotus spp.) have commonly been consumed. This natural food item shows an excellent taste and contains a significant nutrient component concentration, including carbohydrates, proteins, minerals, and vitamins. Besides, numerous research outcome has revealed that oyster mushrooms can reduce and prevent several severe diseases, including cholesterol and hypertension (Agrawal et al., 2010), prostate cancer and breast cancer (Jedinak \& Sliva, 2008). $\quad \beta$-glucan is a main bioactive compound that commonly exists in oyster mushrooms, is linked with lowering the glycaemic response and blood cholesterol levels in vivo (Zhu et al., 2015). The dried oyster mushroom is high in $\beta$-glucan (3.32$25.83 \%)$ and total DF (33.00-56.99\%) content ( $\mathrm{Ng}$ et al., 2017). Moreover, the incorporation of PSP to partially replace wheat flour in a flatbread such as a tortilla is intended to improve nutrient composition since PSP contains a significant amount of $\beta$ glucan, DFs, and protein, as reported by $\mathrm{Ng}$ et al., 2016.

Tortillas are unleavened flatbreads or pancakes made from either corn or wheat flour. It can be used as a substitute for bread and snacks and serve as a principal meal of the human daily diet. Currently, great interest has been created in the development and consumption of tortillas enhanced with numerous nutritive ingredients such as amaranth flour, flaxseed flour, triticale flour, black bean, and soybean (Islas-Hernandez et al., 2007; Rendon-Villalobos et al., 2009; Vaca-Garcia et al., 2011; Grajales-Garcia et al., 2012; Obatolu et al., 2007). Similar to white bread, wheat-based flour tortillas are rich in carbohydrates that produce a high glycaemic response after consumption (Saldana \& Brown, 1984). Therefore, the current study aimed to evaluate the effect of substituting wheat flour with different PSP levels for tortillas production and its effect on nutrient compositions, sensorial acceptability, and GI values.

\section{Material and Methods}

Oyster mushrooms (Pleurotus sajorcaju, PS) grown on a sawdust substrate were utilized in the present study. Clusters of PS, grown within 6-8 $\mathrm{d}$ after spawning, were harvested by using sterile scissors so that no extra mushroom mycelium would be teased. Exactly, $5 \mathrm{~kg}$ harvested mushrooms were dehydrated using the low-heat air-dried drying technique at $50-55^{\circ}$ for $2 \mathrm{hrs}$, established by Anjaad Industries (M) Sdn. Bhd. The dehydrated PSP (yield approximately $10 \% \mathrm{w} / \mathrm{w}$ ) was milled into powder using an electric grinder (Waring Commercial 8010S, USA) and sifted into a fine powder using a sieve with a mesh diameter of $125 \mu \mathrm{m}$. The collected PSP was then kept in screw cap bottles and stored at $4^{\circ} \mathrm{C}$ until further use.

\subsection{Development of Tortilla}

The tortilla was produced in a flatbread shape, adapted from Anton et al., 2008, with a slight modification on the ingredients' composition used. The original ingredient of wheat flour was added with PSP at 5\%, 10\%, and $15 \%$. These PSP-based tortillas were compared with a control tortilla, which was made of $100 \%$ wheat flour (0\% PSP). Firstly, the all-purpose flour was thoroughly mixed with PSP, vegetable fat, baking powder, and salt in a mixing bowl. Then, water was added to the mixture, and then the dough was mixed manually. Next, the mixture was cut into uniformed pieces of $35 \mathrm{~g}$. After that, the dough was manually rounded and allowed to rest for $30 \mathrm{~min}$ for proper hydration. After resting, each ball was then stretched using a baked roller to form a round shape. The flat doughs were cooked on a hot non-stick pan for 1 min per side (Model KX-11K1, Sharp Corporation, Japan). Finally, the cooked tortillas were cooled on a rack for $1 \mathrm{~min}$ and 
packed in four polyethylene plastic bags according to formulations prior to analyses. While waiting for further analyses, the tortillas were sealed after $3 \mathrm{~h}$ and labelled in four different air-tight plastic containers according to their formulations.

\subsection{Analyses of the nutrient composition}

Tortilla samples were analysed for ash, moisture, fat, protein, and total DF according to the standard analytical method (AOAC, 2000). The tortillas' $\beta$-glucan levels were quantified according to the AOAC, 2000, using a Mixed-Linkage $\beta$-glucan Test Kit (Megazyme International Ireland Ltd., Ireland). The tortillas' carbohydrate contents were determined by calculating the percent remaining after all the other components (by difference method). The following formula determined the calorie ( $\mathrm{kcal} / 100 \mathrm{~g}$ ) value of the samples: Carbohydrate: $1 \mathrm{~g}=4$ cal; Fat: 1 $\mathrm{g}=9 \mathrm{cal}$ and Protein: $1 \mathrm{~g}=4 \mathrm{cal}$.

\subsection{Color properties}

The sample color was measured using a Minolta spectrophotometer (CM-3500d Co. Ltd, Osaka, Japan). The instrument was calibrated using a Zero Calibration Box and a White Calibration Plate before analysis, and the average values of the three replicates were reported. The surface color was measured using the $\mathrm{L}^{*}, \mathrm{a}^{*}, \mathrm{~b}^{*}$ scales as lightness (white to black), yellowness (yellow to blue), and redness (red to green) indications, respectively.

\subsection{Sensory evaluation}

Cooked tortilla samples were served to a panel of 60 untrained volunteers. They were randomly selected among staff and students from the School of Health Sciences, Universiti Sains Malaysia. Four samples from the different tortilla formulations were served to each panelist individually. The panelists were asked to indicate the aroma, appearance, color, texture, flavor, aftertaste, and overall acceptability for all samples. A seven-point hedonic rating scale, where 1 corresponded to 'dislike the most', 4 to 'moderately like', and 7 to 'like the most' was used to determine each attribute (Aminah et al., 2000).

\subsection{Glycaemic index (GI) determination}

Fourteen healthy human subjects (three males and eleven females) were randomly selected from staffs and students of Universiti Sains Malaysia, Healthy Campus. The criteria were: age between 18 to 65 years; body mass index (BMI) of 18.5 to $25 \mathrm{~kg} / \mathrm{m}^{2}$. Ethical clearance for this study was approved by the Research Ethics Committee (Human) of Universiti Sains Malaysia. Subjects were served with $25 \mathrm{~g}$ available carbohydrate portions of the reference food and the test foods (FAO/WHO, 1998). The fingertip capillary blood samples $(5 \mu \mathrm{L})$ were collected at fasting, then repeatedly at $15,30,45,60$, 90, and 120 minutes after consuming the test food. The test meals were served with drinking water $(250 \mathrm{ml})$ in each session. Determination of incremental area under the curve (iAUC) was calculated using Microsoft Excel (Version 2007, USA), in which the trapezoid rule was applied. Only the area above the fasting level was included if the blood glucose response value falls below the baseline. The GI of the test foods was then calculated according to FAO/WHO, 1998.

\subsection{Statistical analysis}

Statistical analyses were performed using the GraphPad Prism Software (Version 6.01, USA). The results were expressed as the mean \pm SEM. The results were analysed for significance using one-way analysis of variance (ANOVA). Tukey's post-hoc test was done for pairing comparison. All tests were 2-tailed, and the significant values were set at $\mathrm{p}=0.05$. 


\section{Results and discussion}

\subsection{Nutrients composition}

Generally, all components were found to increase proportionally with the PSP level added into the tortilla formulations except for moisture and carbohydrates, which decreased with increasing PSP levels (Table 1). The moisture contents of both the PSP and wheat flour, which were pre-determined before mixing, were $8.84 \%$ and $11.00 \%$, respectively. The tortilla's moisture contents with PSP incorporated ranged from 16.12 to $19.07 \%$, while the tortilla without PSP contained more moisture $(19.50 \%)$. In the present study, the moisture content was decreased with the increased levels of PSP. Decreased values of moisture content have also been reported by Islas-Hernandez et al., 2007, in corn tortillas with added amaranth flour and flaxseed (Rendon-Villalobos et al., 2009). The dried oyster mushrooms naturally possess water holding capacity and low water content, and this might have caused the lower moisture content detected in the tortilla with added PSP. Moreover, the sugars, starch, and DF that exist in dried PSP might haven't contributed, as they can contain a small amount of water (Mohamed et al., 2010). Concurrently, other findings reported that PSP-enriched cookies contained lower moisture contents than control cookies ( $\mathrm{Ng}$ et al., 2017). Cookies are considered very lowmoisture-content products, as the thermal processing brings down the final moisture content (ranging from 2 to $5 \%$ ) in the food product. On the contrary, increased moisture content values have been documented by Aishah \& Wan Rosli, 2013, in shortened cakes with added PSP. The difference in moisture content is due to the fact that the present study used different types of ingredients and composition and cooking techniques as compared to Aishah \& Wan Rosli, 2013.

Table 1. Nutritional composition of tortilla (g/100 g) added with PSP.

\begin{tabular}{ccccc}
\hline Component & \multicolumn{4}{c}{ Levels of PSP incorporation $(\%)$} \\
$(\%)$ & 0 & 5 & 10 & 15 \\
\hline Moisture & 19.50 & 19.07 & $16.71 \pm 0$. & $16.1 \pm$ \\
& \pm 0.10 & $\pm 0.04^{\mathrm{b}}$ & $05^{\mathrm{cg}}$ & $0.04^{\mathrm{cg}}$ \\
Total ash & $0.66 \pm$ & $0.84 \pm$ & $0.98 \pm$ & $1.14 \pm$ \\
& 0.01 & $0.03^{\mathrm{b}}$ & $0.03^{\mathrm{cd}}$ & $0.03^{\mathrm{chh}}$ \\
Crude fat & $5.60 \pm$ & $5.73 \pm$ & $6.65 \pm$ & $7.60 \pm$ \\
& 0.08 & 0.07 & $0.04^{\mathrm{cg}}$ & $0.05^{\mathrm{cgk}}$ \\
Protein & $8.26 \pm$ & $9.3 \pm$ & $9.72 \pm$ & $10.6 \pm$ \\
& 0.21 & $0.08^{\mathrm{a}}$ & $0.28^{\mathrm{b}}$ & $0.06^{\mathrm{ceh}}$ \\
Carbohydrate & $65.9 \pm$ & $65.05 \pm$ & $65.94 \pm$ & $64.55 \pm$ \\
& 0.18 & $0.17^{\mathrm{a}}$ & $0.21^{\mathrm{d}}$ & $0.14^{\mathrm{bi}}$ \\
Total & $9.31 \pm$ & $9.99 \pm$ & $12.00 \pm$ & $13.62 \pm$ \\
dietary fibre & 0.07 & 0.00 & $0.67^{\mathrm{a}}$ & $0.39^{\mathrm{be}}$ \\
Beta-glucan & $0.69 \pm$ & $1.02 \pm$ & $1.05 \pm$ & $1.21 \pm$ \\
& 0.03 & 0.03 & 0.20 & 0.17 \\
Calorie & $365.99 \pm$ & 368.99 & $386.45 \pm$ & 396.21 \\
$(\mathrm{kcal} / 100 \mathrm{~g})$ & 0.78 & \pm 0.40 & 0.81 & \pm 0.51 \\
\hline $\mathrm{a}=\mathrm{p}<0.05 ; \mathrm{b}=\mathrm{p}<0.01 ; \mathrm{c}=\mathrm{p}<0.0001$ compared
\end{tabular}
to $0 \%$ PSP tortilla; $\mathrm{d}=\mathrm{p}<0.05 ; \mathrm{e}=\mathrm{p}<0.01$; $\mathrm{f}=\mathrm{p}<0.001 ; \mathrm{g}=\mathrm{p}<0.0001$ compared to $5 \%$ PSP tortilla, $\mathrm{h}=\mathrm{p}<0.05 ; \mathrm{i}=\mathrm{p}<0.01 ; \mathrm{j}=\mathrm{p}<0.001$; $\mathrm{k}=\mathrm{p}<0.0001$ compared to $10 \%$ PSP tortilla

The concentration of the total ash significantly increased with increasing PSP levels in the tortilla formulation. The control tortilla contained $0.66 \%$ total ash, while the tortilla formulations with $5 \%, 10 \%$, and $15 \%$ PSF were recorded as having 0.84, 0.98, and $1.14 \%$ total ash, respectively. In agreement with other studies' results, total ash increments were also observed in cookies $(\mathrm{Ng}$ et al., 2017) and shortened cakes (Aishah, 2013) added with PSP. Similar findings were also obtained for tortillas made with a blend of quality protein maize and black bean (Grajales-Garcia et al., 2012), home-made maize tortilla with soybean (Obatolu et al., 2007), and paratha bread added with PSP 
(Aishah \& Wan Rosli, 2013). From a nutrition science standpoint, PSP could improve the tortilla's mineral contents; this is supported by the findings obtained in the present work, which indicated that the ash contents in the tortilla increased with increasing PSP levels.

Fat contents ranged from 5.73 to $7.60 \%$ in the tortilla with PSP incorporated, while the control tortilla contained less fat $(5.60 \%)$. The tortilla added with 5\% PSP had $5.73 \%$ of fat but not significantly as compared to the control sample. On the other hand, 10 and $15 \%$ PSP tortillas recorded 6.65 and $7.60 \%$ of crude fat, respectively, and significantly higher than the control sample. In accordance with the findings of other studies, the increments of fat were also observed for tortillas made with different pigmented varieties of corn (Islas-Hernandez et al., 2007, and tortilla prepared with chia seeds (Rendon-Villalobos et al., 2012).

An increment of protein content in the tortilla was found in line with the PSP level used to replace the wheat flour partially. The control tortilla's protein concentration was $8.26 \%$ and increased to 9.31, 9.72, and $10.60 \%$ when incorporated with 5,10 , and $15 \%$ PSP, respectively. The protein content of PSP-based tortillas was significantly higher than the control tortilla. Tortilla added with $15 \%$ PSP contain a significantly higher protein amount than 5 and 10\% PSP tortillas. However, there was no significant difference between 5 and 10\% PSP tortillas in protein content. The increase in the protein content in PSP-added tortilla might be important to increase the essential amino acid level that is deficient in wheat flour. This showed that the nutrient content of the tortilla substituted with PSP was better than the control tortilla. This might be due to the fact that the PSP used in the present work had a significant amount of protein, ranging between 21.01 to $22.41 \%$. Similar findings related to the increased values of protein in tortilla were also observed in other studies (tortilla formulated with amaranth flour (Islas-Hernandez et al., 2007), flaxseed flour (Rendon-Villalobos et al., 2008), black bean (Grajales-Garcia et al., 2012), maize-bean flour (Hernandez-Salazar et al., 2006), bean flour (Anton et al., 2008).

The carbohydrate contents in the tortilla were found to decrease with increasing PSP levels slightly. The carbohydrate content of the control tortilla $(65.98 \%)$ did not differ significantly with the addition of $5 \%, 10 \%$, and $15 \%$ PSP, which resulted in $65.05 \%$, $65.94 \%$, and $64.55 \%$ carbohydrates. A similar finding was presented by $\mathrm{Ng}$ et al., 2017, who fortified cookies with PSP. The present results were also in accordance to the study performed by Obatolu et al., 2007, and Rendon-Villalobos et al., 2008, who found a decreased in carbohydrate contents when the increased levels of soybean and flaxseed incorporated in the tortilla. However, in another study, Aishah \& Wan Rosli, 2013, documented that carbohydrate contents increased when PSP was incorporated in shortened cakes, although this might be due to the shortened cakes' different formulations.

The TDF contents in the tortilla with PSP incorporated ranged from $9.99 \%$ to $13.62 \%$, while the control tortilla contained less TDF $(9.31 \%)$. Both the $10 \%$ and $15 \%$ PSF tortilla (12.00\% and $13.62 \%$ TDF) were found to be significantly higher than the control tortilla in TDF. This finding could be attributed to the natural TDF concentration contributed by the PSP. Hence, this result signifies that PSP could be potentially considered as an alternative food ingredient to improve the TDF content of tortillas and other processed food products. Earlier studies performed by $\mathrm{Ng}$ et al., 2017, and Aishah, \& Wan Rosli, 2013, also found that the incorporation of PSP increased the TDF content. Also, Torres et al., 2007, and Prabhasankar et al., 2009, reported that TDF contents were increased 
Does oyster mushroom (Pleurotus sajorcaju) powder addition improve nutrient composition, sensory acceptability, and glycaemic index (GI) of flatbread (Tortilla)?

when wheat flours were replaced in germinated Cajanus cajan seeds and different types of seaweeds in their products. The DF assists manage peristalsis (promoting bowel motion), and the slowing of peristalsis leads to constipation. Besides the discomfort it can bring, constipation has been linked with a range of illnesses and disorders, including varicose veins. The DF is also a good binder of toxicants as well as certain nutrients in foods. Even though toxicants' entrapment can protect the body, excess fibre intake may limit the absorption of some essential minerals and vitamins (Shewfelt, 2009). Previously, both studies conducted by Rendon-Villalobos et al., 2009, and GrajalesGarcia et al., 2012, have shown the improvement of TDF in tortilla incorporated with flaxseed and a blend of maize and black bean.

\section{2. $\beta$-glucan content}

Among all formulations, the $\beta$-glucan content was the highest in the tortilla with 15\% PSP added $(1.21 \%)$. The results showed that the $15 \%$ PSP tortilla had significantly higher $\beta$ glucan than the control and the 5\% PSP tortilla (Table 1). Previously, linearly increasing levels of $\beta$-glucan contents have also been reported with increasing PSP levels substituted in cookies ( $\mathrm{Ng}$ et al., 2017) and shortened cakes (Aishah and Wan Rosli, 2013). Dried oyster mushrooms have been considered a functional food due to their nutritional and medicinal characteristics that are associatable with the existence of $\beta$ glucan. They have exhibited significant beneficial health effects, such as an antitumour nature, hypocholesterolaemia, and immunomodulatory activities (Kim et al., 2011; Samsudin and Abdullah, 2019).

\subsection{Calorific value (kcal/100 g)}

The tortilla's calorific values were found to increase with increasing PSP levels even though these were not significant. Increasing the PSP levels in the tortilla formulations resulted in increasing the calorific value by $0.8-8.0 \%$ (Table 1). This finding was in agreement with Torres et al., 2007, who observed that spaghetti supplemented with germinated pigeon pea flour showed an increase in the caloric value $(358.19 \mathrm{kcal} / 100$ g) when compared with control spaghetti (320 kcal/100 g).

\subsection{Color properties}

In general, redness $\left(\mathrm{a}^{*}\right)$ and yellowness $\left(\mathrm{b}^{*}\right)$ attributes were significantly higher with increasing PSP levels, but lightness ( $\left.\mathrm{L}^{*}\right)$ was significantly lower with increasing PSP levels (Table 2). The incorporation of PSP into the tortilla formulations resulted in lower $\mathrm{L}^{*}$ values as compared to the control tortilla; the lightness of the tortilla with PSP added at several levels $(5 \%, 10 \%$, and $15 \%$ ) was detected between 57.47 to $65.18 \mathrm{~L}^{*}$ values while the control tortilla had a 76.09 lightness intensity. Another study also found out that $L^{*}$ value increased significantly when ground oyster mushroom was added at different levels in herbal seasoning products (Saiful Bahri, 2015). The substitution of PSP into the tortilla formulations resulted in higher $\mathrm{a}^{*}$ values than the control tortilla. Redness in the tortilla with $0 \%, 5 \%, 10 \%$, and $15 \%$ PSP levels was recorded at $-1.17,2.75,4.12$ and $5.68 \mathrm{a}^{*}$ values, respectively. Concurrently, increased $a^{*}$ value have also been observed when herbal seasoning product was incorporated with different levels of ground oyster mushroom (Saiful Bahri, 2015). On the other hand, a study by $\mathrm{Ng}$ et al., 2017, regarding PSP-enriched cookies reported opposing findings. This may be due to the different ingredients and the dissimilarity between the cooking processes conducted in $\mathrm{Ng}$ et al., 2017, study as compared to the present work. 
Table 2. Effect of PSP on color of tortilla.

\begin{tabular}{ccccc}
\hline \multirow{2}{*}{ Scales } & \multicolumn{4}{c}{ Levels of PSP incorporation (\%) } \\
\cline { 2 - 5 } & 0 & 5 & 10 & 15 \\
\hline$L^{*}$ & 76.09 & 65.18 & 63.44 & $57.47 \pm$ \\
& \pm 0.01 & \pm & \pm & $0.01^{\text {acd }}$ \\
& & $0.03^{\mathrm{a}}$ & $0.01^{\mathrm{ac}}$ \\
$a^{*}$ & $-1.17 \pm$ & $2.75 \pm$ & $4.12 \pm$ & $5.68 \pm$ \\
& 0.01 & $0.0^{\mathrm{a}}$ & $0.01^{\mathrm{ac}}$ & $0.01^{\mathrm{acd}}$ \\
$b^{*}$ & 21.75 & 22.71 & 22.81 & $24.15 \pm$ \\
& \pm 0.01 & \pm & $\pm 0.0^{\mathrm{ab}}$ & $0.0^{\mathrm{acd}}$ \\
& \multicolumn{4}{c}{$0.02^{\mathrm{a}}$} \\
\hline
\end{tabular}

$\mathrm{a}=\mathrm{p}<0.0001$ compared to $0 \%$ PSP tortilla, $\mathrm{b}=\mathrm{p}<0.001 ; \mathrm{c}=\mathrm{p}<0.0001$ compared to $5 \%$ PSP tortilla

$\mathrm{d}=\mathrm{p}<0.0001$ compared to $10 \%$ PSP tortilla

\subsection{Sensory acceptability}

Tortilla fortified with up to a $15 \%$ PSP substitution was generally well accepted (Table 3). A rating score of 4 and above indicated that the panelists favored the sample (Nordiana et al., 2019). Sensory evaluation studies demonstrated that there were no significant differences for control tortilla as compared to pasta with 5\% PSP for all attributes. In fact, PSP-based tortillas were found to receive higher scores for aroma, color, and flavor than control tortilla. In this study, the $5 \%$ and $10 \%$ PSP tortillas score were significantly higher than the control tortilla in all attributes except for aftertaste. Also, 5\% PSP tortilla scored the highest values for all sensory attributes. Tortilla incorporated with 10 and 15\% PSP were found to be comparable with control tortilla (0\% PSP) in all attributes except for aftertaste and appearance. The current result demonstrates that panels prefer tortilla sample, which contains up to $15 \%$ of PSP for all attributes (the score values range from 4.00 to 4.54$)$. In fact, the control sample has the lowest scores for aroma, color, flavor, and texture. The tortilla's flavor was enhanced by incorporating PSP, which provided this tortilla with a typical, pleasant oyster mushroom flavor. Therefore, it can be suggested that the flavor and texture acceptance of tortilla could be improved by adding up to $10 \%$ and $15 \%$ PSP. According to Obatolu et al., 2007, soybean's addition did not significantly affect the tortilla's overall acceptability. Likewise, bean tortillas' overall acceptability was significantly higher than the wheat control (Anton et al., 2009). Even though the sensory scores of tortillas added with $10 \%$ are relatively higher than $15 \%$ PSPtortilla for all attributes, it was not significant. This value (15\% PSP level) was chosen for GI determination since the higher the DF value, the higher the product's tendency to have a low GI value ( $\mathrm{Ng}$ et al., 2017).

Table 3. Sensory analysis values of tortillas added with different levels of PSP.

\begin{tabular}{|c|c|c|c|c|}
\hline \multirow[t]{2}{*}{ Attributes } & \multicolumn{4}{|c|}{$\begin{array}{l}\text { Levels of PSP incorporation } \\
(\%)\end{array}$} \\
\hline & 0 & 5 & 10 & 15 \\
\hline \multirow[t]{3}{*}{ Appearance } & 4.02 & 4.75 & 4.56 & 4.00 \\
\hline & \pm 0.21 & \pm & \pm & \pm \\
\hline & & $0.16^{\mathrm{a}}$ & 0.15 & $0.18^{\mathrm{d}}$ \\
\hline \multirow[t]{3}{*}{ Aroma } & $3.53 \pm$ & 4.54 & 4.32 & 4.54 \\
\hline & 0.18 & \pm & \pm & \pm \\
\hline & & $0.15^{\mathrm{c}}$ & $0.16^{\mathrm{b}}$ & $0.17^{\mathrm{c}}$ \\
\hline \multirow[t]{3}{*}{ Colour } & $3.97 \pm$ & 4.93 & 4.44 & 4.37 \\
\hline & 0.18 & \pm & \pm & \pm \\
\hline & & $0.16^{\mathrm{c}}$ & 0.15 & 0.18 \\
\hline \multirow[t]{3}{*}{ Flavour } & $3.95 \pm$ & 4.73 & 4.19 & 4.20 \\
\hline & 0.19 & \pm & \pm & \pm \\
\hline & & $0.17^{\mathrm{a}}$ & 0.17 & 0.19 \\
\hline \multirow{3}{*}{ Texture } & $4.31 \pm$ & 4.66 & 4.44 & 4.39 \\
\hline & 0.17 & \pm & \pm & \pm \\
\hline & & 0.15 & 0.15 & 0.17 \\
\hline \multirow[t]{3}{*}{ Aftertaste } & $4.39 \pm$ & 4.80 & 4.36 & 4.09 \\
\hline & 0.17 & \pm & \pm & \pm \\
\hline & & 0.17 & 0.17 & $0.19^{\mathrm{d}}$ \\
\hline \multirow{3}{*}{$\begin{array}{c}\text { Overall } \\
\text { acceptance }\end{array}$} & $4.34 \pm$ & 4.90 & 4.46 & 4.32 \\
\hline & 0.16 & \pm & \pm & \pm \\
\hline & & 0.15 & 0.16 & 0.17 \\
\hline
\end{tabular}


Does oyster mushroom (Pleurotus sajorcaju) powder addition improve nutrient composition, sensory acceptability, and glycaemic index (GI) of flatbread (Tortilla)?

\subsection{The GI Value of Tortilla}

The GI is a measure of the potential of a carbohydrate-containing food to elevate blood glucose concentration after ingestion. The GI and iAUC values of the tortilla formulated with PSF and reference glucose are shown in Table 4. Control tortilla had an intermediate GI value (58) while $15 \%$ PSP tortilla had a low GI (53). Tortilla added with $15 \%$ PSP revealed a small reduction in GI compared to control tortilla. However, this decrement was not significant. These outcomes propose that intestinal glucose release after ingestion of PSP-added tortilla might be lesser than when the control tortilla was ingested. Another possible explanation is that the higher DF content occurred in $15 \%$ PSP tortilla $(13.62 \%)$ than $9.31 \%$ in the control tortilla as described previously in Table 2. The increased amount of total DF in 15\% PSP tortilla might be accountable for developing a polysaccharide linkage that can capture the starch granules during processing. The entrapment of starch decreases availability to enzymatic degradation, and consequently, decreases the sugars released in the blood (Foschia et al., 2015). Besides, the higher protein content also can be accountable $(10.60 \%$ in $15 \%$ PSP tortilla compared to $8.26 \%$ in control tortilla). It was formerly stated that the existence of protein in the food matrix affects the degree of starch breakdown (Kim et al., 2008). The higher amount of protein probably builds a tougher network, therefore decreasing the starch accessibility to enzymatic attack.

Table 4. Glucose response (iAUC) and GI values of tortilla $(\mathrm{n}=14)$

\begin{tabular}{ccc}
\hline Test food & $\begin{array}{c}\text { iAUC }(\mathrm{mmol} x \\
\min / \mathrm{l})\end{array}$ & GI \\
\hline 0\% PSP tortilla & $119 \pm 17^{\mathrm{a}}$ & $58 \pm 8^{\mathrm{b}}$ \\
15\% PSP tortilla & $106 \pm 11^{\mathrm{b}}$ & $53 \pm 5^{\mathrm{b}}$ \\
Glucose & $201 \pm 9$ & 100 \\
\hline $\mathrm{a}=\mathrm{p}<0.001 ; \mathrm{b}=\mathrm{p}<0.0001$ compared to glucose
\end{tabular}

Moreover, another explanation can be due to higher $\beta$-glucan content $(1.21 \%$ in $15 \%$ PSP tortilla compared to $0.69 \%$ in control tortilla). The useful properties of $\beta$-glucans have been recognized by their capability to increase lumen viscosity (Dikeman \& Fahey, 2006; Wood, 2002). It has been advocated that $\beta$-glucan, by increasing the viscosity of the gastrointestinal tract contents, interrupts gastric emptying and the intestinal absorption of nutrients like digestible carbohydrates and thus decreases postprandial glycemia and insulin excretion (Lazaridou \& Biliaderis, 2007). This might be suggested that the helpful action of $\beta$-glucan is mostly because of delayed and reduced carbohydrate absorption from the gut and does not result from the effects of metabolites formed by fermentation of $\beta$-glucan in the colon. It is also possible that $\beta$-glucan not only declines the postprandial glucose response (GR) in the gastrointestinal tract due to high viscosity but also decreases starch breakdown by $\alpha$ amylase (Lazaridou \& Biliaderis, 2007). A former study indicated that the incorporation of $0,2,4$, and $8 \mathrm{~g}$ of barley $\beta$-glucan in a $75 \mathrm{~g}$ glucose drink reduced postprandial glucose and insulin levels in a dose-dependent manner (Panahi et al., 2005). Vitaglione et $a l ., 2009$, found out that using $3 \%$ of $\beta$-glucan from Glucagel significantly reduced $(9 \%$ less) the glucose response of bread.

Generally, the changes in the level of nutritional composition and the GI decline show that the incorporation of PSP in the mixture plays the most major role in the overall starch digestibility. Low GI carbohydrates are usually considered to be food with GI values of 55 and below. Foods that have a GI between 56 and 69 are considered to have a moderate GR, and those GI values 70 and above have a high GR. Similarly, in a study done by Grajales-García et al., 2012, found out that the incorporation 
of bean reduced the predicted GI (pGI) value of tortilla (79.8) that was higher (88) in maize tortilla. Also, Rendon-Villalobos et al., 2008, observed that the control sample (common white tortilla) exhibited a pGI of 101, and those tortillas fortified with flaxseed flour had much lower pGI values (73-88). In another study, fresh white corn tortilla had a pGI of 97.5, but blue corn tortillas' value was significantly lower (85.8) (Hernandez-Uribe et al., 2007). Contradictorily, IslasHernandez et al., 2007, observed that amaranth-containing tortilla showed higher pGI (107) than corn tortilla (control) (103).

There was no significant difference between iAUC of control tortilla and $15 \%$ PSP tortilla (Figure 1). On the other hand, the iAUC and GI values of 0 and $15 \%$ PSP tortillas were significantly lower than those of glucose. For both test foods, the blood glucose levels (BGLs) were significantly lesser at 15, 30, 45, and $60 \mathrm{~min}$. At 0, 90, and $120 \mathrm{~min}$, there was no significant difference of BGLs between glucose and two test foods (0 and 15\% PSP tortillas). Moreover, the peak BGLs have reached a maximum at 45 min for the glucose and test foods. Besides, the BGLs also began to gradually decline after $45 \mathrm{~min}$ for all samples.

\section{Conclusion}

Fortification of PSP could possibly be used for the partial substitution of wheat flour in tortilla production because of its ability to improve the nutritional quality of the original food product without ignoring the palatability aspects. Oyster mushrooms are considered a sub-product of little commercial value and an insignificant industrial advantage; so, for oyster mushroom growers and tortilla product makers, this represents a possibility of diversifying and expanding their markets.

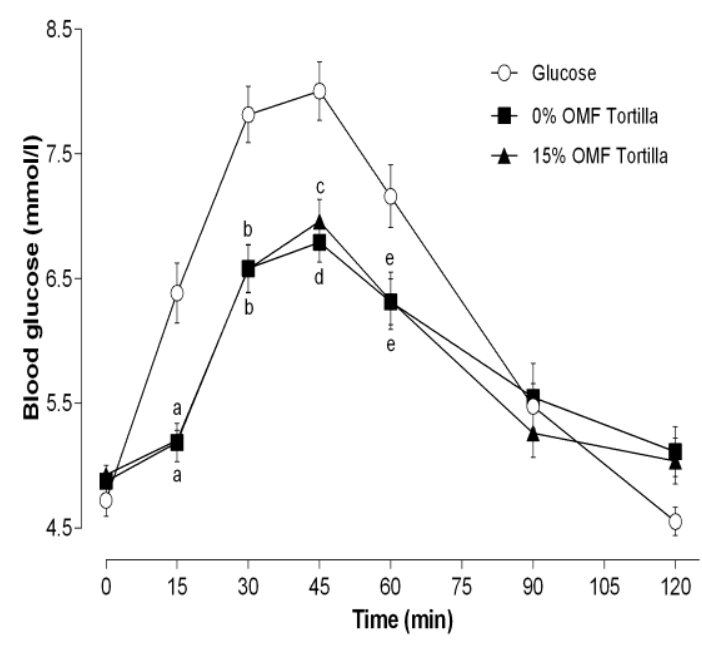

Fig. 1. BGLs in response to the addition of $0 \%$ and $15 \%$ PSP in tortilla.

$\mathrm{a}=\mathrm{p}<0.0001$ compared to glucose at $15 \mathrm{~min}$; $\mathrm{b}=\mathrm{p}<0.001$ compared to glucose at $30 \mathrm{~min}$; $\mathrm{c}=\mathrm{p}<0.01 ; \mathrm{d}=\mathrm{p}<0.001$ compared to glucose at $45 \mathrm{~min}, \mathrm{e}=\mathrm{p}<0.05$ compared to glucose at 60 min; Glucose represent glucose drink as control.

An addition of 15\% PSP in the tortilla formulation was found to increase nutritional values, affect color properties, improve sensorial attributes, and reduce GI value.

\section{ACKNOWLEDGEMENTS}

The authors would like to acknowledge the Ministry of Education of Malaysia for providing a scholarship under the MyBrain15 Programme and the School of Health Sciences, Universiti Sains Malaysia, for providing the research facilities. An acknowledgement is also going to Wan Rosidi Wan Ishak. 


\section{References}

Agrawal, R. P.; Chopra, A.; Lavekar, G. S.; Padhi, M. M.; Srikanth, N. et al. (2010). Effect of oyster mushroom on glycemia, lipid profile, and quality of life in T2D patients. Australian Journal of Medical Herbalism, 22(2), 50-54.

Aishah, M. S. \& Wan Rosli, W. I. (2013). The effect of addition of oyster mushroom (Pleurotus sajor-caju) on nutrient composition and sensory acceptation of selected wheat- and rice-based products. International Food Research Journal, 20(1), 1337-1342.

\section{American Association of Cereal Chemists (AACC). (2000). Method 66-50 - measurement of optimum cooking time of pasta. In Approved Methods of the American Association of Cereal Chemist (10th ed). USA: AACC.}

Aminah, A. (2000). Panduan Makmal Penilaian Sensori. Bangi: UKM Press.

Anton, A. A.; Lukow, O. M.; Fulcher, R. G. \& Arntfield, S. D. (2009). Shelf stability and sensory properties of flour tortillas fortified with pinto bean (Phaseolus vulgaris L.) flour: Effects of hydrocolloid addition. LWT - Food Science and Technology, 42, 23-29.

Aravind, N.; Sissons, M. \& Fellows, C. M. (2012). Effect of soluble fibre (guar gum and carboxymethylcellulose) addition on technological, sensory and structural properties of durum wheat spaghetti. Food Chemistry, 131(3), 893-900.

Association of Official Analytical Chemists (AOAC). 2000. Official method of analysis of the Association of Official Analytical Chemists. 15th ed. Washington D.C.: AOAC International.
Bobek, P., Nosalova, V. \& Cerna, S. (2001). Effect of pleuran ( $\beta$-glucan from Pleurotus ostreatus) in diet or drinking fluid on colitis rats. Nahrung, 45(5), 360-363.

Dhingra, D.; Michael, M.; Rajput, H., \& Patil, R. T. (2012). Dietary fibre in foods: a review. Journal of food science and technology, 49(3), 255-266.

Dikeman, C. L., \& Fahey, G. C. (2006). Viscosity as related to dietary fibre: A review. Critical Reviews in Food Science and Nutrition, 46, 649-663.

FAO/WHO (1998). Carbohydrate in Human Nutrition. Report of a Joint Expert FAO/WHO Consultation. FAO Food and Nutrition Paper 66. Food and Agriculture Organization, Rome. 140.

Gallegos-Infante, J. A.; Bello-Perez, L. A.; Rocha Guzman, N. E.; Gonzalez-Laredo, R. F. \& Avila Ontiveros, M. (2010). Effect of the addition of common bean (Phaseolus vulgaris $L$.) flour on the in vitro digestibility of starch and undigestible carbohydrates in spaghetti. Journal of Food Science, 75(5), H151- H156.

Grajales-García, E. M.; Osorio-Díaz, P.; Goñi, I.; Hervert-Hernández, D.; GuzmánMaldonado, S. H. et al. (2012). Chemical Composition, Starch Digestibility and Antioxidant Capacity of Tortilla Made with a Blend of Quality Protein Maize and Black Bean. International Journal of Molecular Sciences, 13, 286-301.

Islas-Hernandez, J.J.; Rendon-Villalobos, R.; Agama-Acevedo, E.; Tovar, J. \& BelloPerez, L. A. (2007). Chemical composition and in vitro starch digestibility of corn tortillas with added amaranth flour. Journal of the Science of Food and Agriculture, 87, 2348-2352. 
Jedinak, A. and Sliva, D. (2008). Pleurotus ostreatus inhibits proliferation of human breast and colon cancer cells through p53dependent as well as p53-independent pathway. International Journal of Oncology, 33(6), 1307-1313.

Jochem, C. and Leitzmann, M. (2016). Obesity and colorectal cancer. In Obesity and Cancer: 17-41. Springer, Cham.

Kim, J.; Lee, S. M.; Bae, I. Y.; Park, H. G.; Lee, H. et al. (2011). (1-3) (1-6)- $\beta$-Glucanenriched materials from Lentinus edodes mushroom as a high-fibre and low-calorie flour substitute for baked foods. Journal of the Science of Food and Agriculture, 91(10), 1915- 1919.

Lazaridou, A., \& Biliaderis, C. G. (2007). Molecular aspects of cereal $\beta$-glucan functionality: physical properties, technological applications, and physiological effects. Journal of Cereal Science, 46, 101-8.

Mohamed, A.; Xu, J. and Singh, M. (2010). Yeast leavened banana bread: Formulation, processing, color, and texture analysis. Food Chemistry, 118(3), 620-626.

National health and morbidity survey (NHMS) (2015). Non-communicable diseases, risk factors, and other health problems (volume II). Malaysia: IPHM.

Ng S. H.; Wan Ahmad, W. A. N., and Wan Ishak, W. R. (2016). Quality characteristics of Pleurotus sajor-caju powder: study on nutritional compositions, functional properties and storage stability. Sains Malaysiana, 45(11), 1617-1623.

Ng, S. H.; Robert, S. D.; Wan Ahmad, W. A. N. and Wan Ishak, W. R. (2017). Incorporation of dietary fibre-rich oyster mushroom (Pleurotus sajor-caju) powder improves postprandial glycaemic response by interfering with starch granule structure and starch digestibility of biscuit. Food Chemistry, 227, 358-368.

Nordiana, A. B.; Wan Rosli, W. I., \& Wan Amir Nizam, W. A. (2019). The effect of oyster mushroom (Pleurotus sajor-caju) flour incorporation on the physicochemical quality and sensorial acceptability of pasta. International Food Research Journal, 26(4), 1249-1257

Obatolu, V. A.; Augustine, O. \& Iken, J. E. (2007). Improvement of home-made maize tortilla with soybean. International Journal of Food Science and Technology, 42, 420-426.

Padalino, L.; Mastromatteo, M.; Lecce, L.; Cozzolino, F. \& Del Nobile, M. A. (2013). Manufacture and characterization of glutenfree spaghetti enriched with vegetable flour. Journal of Cereal Science, 57(3), 333-342.

Panahi, S.; Chau, V.; Cornelius, V.; Ezatagha, A. \& Jenkins, A. (2005). $\square-$ glucan from two different sources of oat concentrates affecting postprandial glycemia in relation to the level of viscosity. Presented at the Natural Health Products Conference; Vancouver, BC, Canada; February 2005.

Prabhasankar, P.; Ganesan, P.; Bhaskar, N.; Hirose, A.; Stephen, N. et al. (2009). Edible Japanese seaweed, wakame (Undaria pinnatifida) as an ingredient in pasta: chemical, functional and structural evaluation. Food Chemistry, 115(2), 501508.

Pratesi, R. (2012). Green banana pasta: an alternative for gluten-free diets. Journal of the Academy of Nutrition and Dietetics, 112(7), 1068-1072.

Rendon-Villalobos, J. R.; Bello-Perez, L. A.; Agama-Acevedo, E.; Islas-Hernandez, J. J.; Osorio-Diaz, P. et al. (2009). 
Composition and characteristics of oil extracted from flaxseed-added corn tortilla. Food Chemistry, 117, 83-87.

Saiful Bahri, S. (2015). The effect of ground oyster mushroom (Pleurotus sajor-caju) in the nutritional enhancement, physicochemical properties, and structural changes of herbal seasoning. MSc. thesis, Universiti Sains Malaysia.

Saldana, G., \& Brown, H. E. (1984). Nutritional composition of corn and flour tortillas. Journal of Food Science, 49, 12021209.

Samsudin, N. I. P. \& Abdullah, N. (2019). Edible mushrooms from Malaysia; a literature review on their nutritional and medicinal properties. International Food Research Journal, 26(1), 11-31.

Shewfelt, R. L. 2009. Introducing food science. 1st ed. United States: CRC Press.

Torres, A.; Frias, J.; Granito, M., and Vidal-Valverde, C. (2007). Germinated Cajanus cajan seeds as ingredients in pasta products: Chemical, biological and sensory evaluation. Food Chemistry, 101(1), 202211.

Unwin, N. \& Alberti, K. G. (2006). Chronic non-communicable diseases. Annals of Tropical Medicine and Parasitology, 100, 455-464.

Vaca-Garcia, V. M.; Martínez-Rued, C. G.; Mariezcurrena-Berasain, M. D. \& Dominguez-Lopez, A. (2011). Functional properties of tortillas with triticale flour as a partial substitute of nixtamalized corn flour. LWT-Food Science and Technology, 44, 1383-1387.

Vitaglione, P.; Barone Lumaga, R.; Stanzione, A.; Scalfi, L. \& Fogliano, V. (2009). $\beta$-glucan-enriched bread reduces energy intake and modifies plasma ghrelin and peptide YY concentrations in the short term. Appetite, 53, 338-44.

Wood, J. A. (2009). Texture, processing, and organoleptic properties of chickpea fortified spaghetti with insights to the underlying mechanisms of traditional durum pasta quality. Journal of Cereal Science, 49(1), 128- 133.

Zheng, Y.; Ley, S. H. \& Hu, F. B. (2018). Global aetiology and epidemiology of type 2 diabetes mellitus and its complications. Nature Reviews Endocrinology, 14(2), 88.

Zhu, F.; Du, B.; Bian, Z. \& Xu, B. (2015). $\beta$-glucans from edible and medicinal mushrooms: Biological, characteristics and physicochemical activities. Journal of Food Composition and Analysis, 41, 165-173.

Submitted: $23 / 04 / 2020$

Revised : 23/06/2020

Accepted : 26/07/2020

DOI : 10.48129/kjs.v48i2.9399 
Wan Rosli WAN ISHAK, Wan Amir Nizam WAN AHMAD, Nordiana ABU BAKAR $-2-$

Kuwait Journal of Science 